\title{
Toddlers' Prosocial Behavior: From Instrumental to Empathic to Altruistic Helping
}

\author{
Margarita Svetlova, Sara R. Nichols, and Celia A. Brownell \\ University of Pittsburgh
}

\begin{abstract}
The study explored how the meaning of prosocial behavior changes over toddlerhood. Sixty-five 18- and 30month-olds could help an adult in 3 contexts: instrumental (action based), empathic (emotion based), and altruistic (costly). Children at both ages helped readily in instrumental tasks. For 18-month-olds, empathic helping was significantly more difficult than instrumental helping and required greater communication from the adult about her needs. Altruistic helping, which involved giving up an object of the child's own, was the most difficult for children at both ages. Findings suggest that over the 2nd year of life, prosocial behavior develops from relying on action understanding and explicit communications to understanding others' emotions from subtle cues. Developmental trajectories of social-cognitive and motivational components of early helping are discussed.
\end{abstract}

Human children begin to behave prosocially very early in life, before 2 years of age. Studies have documented 1-year-olds' abilities to comfort others in distress, participate in household tasks, and help adults by bringing or pointing to out-of-reach objects (Liszkowski, Carpenter, Striano, \& Tomasello, 2006; Rheingold, 1982; Warneken \& Tomasello, 2006, 2007; Zahn-Waxler, Radke-Yarrow, Wagner, \& Chapman, 1992). These apparently prosocial acts, emerging so early in ontogeny, have been of interest to social, developmental, and evolutionary psychologists as possible precursors to such human-specific characteristics as concern for others, cooperation and, ultimately, altruism (Fehr \& Rockenbach, 2004; Piliavin \& Charng, 1990; Stevens \& Hauser, 2004; Warneken \& Tomasello, in press). The origins of these early behaviors, however, are not entirely understood, and the mechanisms underlying them remain a matter of debate. If prosocial responding in adults is driven by understanding others' emotions and desires in

This research was supported in part by grants from the National Institute of Child Health and Human Development, HD043971 and HD055283, to the last author. Portions of this research were presented at the International Conference on Infant Studies. We thank all the children and parents who volunteered their time to participate in this study. Special thanks to Ranita Anderson, Catie Henderson, Maryam Khatami, Liz Posti, Stephanie Sivers, Hilarie Stern, and Emily Yarrison for assistance with recruitment, data collection, and coding.

Correspondence concerning this article should be addressed to Margarita Svetlova, Department of Psychology, University of Pittsburgh, Pittsburgh, PA 15260. Electronic mail may be sent to mas53@pitt.edu. combination with a motivation to act on others' behalf (Batson, Ahmad, Powell, \& Stocks, 2008), how can we explain prosocial acts in very young children who have still rudimentary social-cognitive abilities and emergent other-oriented motivational systems?

Current theory and research provide different, sometimes contrasting, views about contributors to the early development of prosocial behavior. Some have proposed that infants' interest in people and their actions combined with basic affiliative and imitative tendencies lie at the root of their initial prosocial responses (Grusec, 2006; Hay \& Cook, 2007; Rheingold, 1982). Others maintain that the critical contributor to early prosocial behavior is the developing ability to differentiate another's internal states from one's own and to relate one's own emotions and needs to another's in order to act on the other's behalf (Bischof-Kohler, 1991; Mascolo \& Fischer, 2007; Moore, 2007; Zahn-Waxler \& RadkeYarrow, 1990). Still others argue for an innate biological substrate for empathy and altruism in infants (Hoffman, 1975; Tomasello, 2008; ZahnWaxler, Robinson, \& Emde, 1992), in part because some prosocial behaviors appear to be uniquely human and emerge before formal socialization begins, suggesting that children may start out being naturally altruistic (Silk et al., 2005; Warneken \& Tomasello, 2009).

(C) 2010 The Authors

Child Development (C) 2010 Society for Research in Child Development, Inc. All rights reserved. 0009-3920/2010/8106-0015 
These different theoretical perspectives place different emphasis on the social-cognitive and motivational components of early prosocial responding. In addition, the nature of each of these components may differ as a function of age, giving the same behavior (e.g., bringing something to someone) different meaning depending on the child's socialcognitive and motivational competences. Prosocial behavior of an infant or toddler may be driven by different forms of social understanding than the same behavior exhibited by an older child or an adult. For example, infants may first interpret others' emotional expressions and behaviors as being about the objects to which they are directed rather than about the other person's mental states or psychological attitudes (Gergely, Egyed, \& Kiraly, 2007). Correspondingly, young children's social responses may be based on less sophisticated inferences about the minds of others, or on even simpler mechanisms such as reading behavioral cues or understanding the contingencies between behavior and its outcomes (e.g., Moore \& Povinelli, 2007; Perner \& Ruffman, 2005).

We can ask, then, to what extent do 1-year-olds who help their parents empty the dishwasher, wash the dog, sweep up spilled cereal, and the like, do so out of caring concern for the parent's needs as opposed to being interested in the action itself, enjoying the social exchange, or even relishing the praise that often follows? What inferences do toddlers make about parents' desires, feelings, or needs when they help? When are they able to be altruistic, giving up something of value knowingly and voluntarily? One way to clarify such questions is to compare children's performance in situations that require the same basic behavioral competence but that differ with respect to their underlying understanding and motivation.

During the 2nd year of life, social understanding becomes increasingly "mentalistic" (Flavell, 1999), and many aspects of social behavior are transformed (see Brownell \& Kopp, 2007), making this period particularly relevant for investigating such issues. In the current study, we examined helping behavior in 1- and 2-year-olds, a period when children's social understanding rapidly develops-and when prosocial responding first emerges. We presented toddlers with tasks that were similar behaviorally but differed in their specific social-cognitive and motivational demands. Our premise was that if children behave prosocially in versions without the relevant demand and fail to do so in corresponding versions with that demand, we would be able to isolate specific components of prosocial responding that are and are not yet in place at a given age. The factors that we experimentally manipulated were the nature of the inference that the child had to make about the other's need, the cost of helping to the child, and the amount of communicative support available to the child about the other's need and how to help. By contrasting the conditions under which 1-year-olds help with those under which 2-year-olds help, we aimed to shed light on developmental changes in the sources of early prosocial behavior.

\section{Instrumental Versus Empathic Helping}

The 2nd year of life is witness to major developmental change in prosocial behavior. Instrumental helping, or assisting another in achieving an actionbased goal such as searching for or getting something out of reach, appears by 12-14 months of age (Liszkowski et al., 2006; Warneken \& Tomasello, 2007), presumably deriving from early-developing understanding of goals and goal-directed behaviors (Woodward, 1998). The ability to respond prosocially to others' emotional distress emerges somewhat later, with a significant increase between 18 and 24 months of age in expressions of concern and comforting behavior toward others in pain (Zahn-Waxler, Radke-Yarrow, et al., 1992). This is associated with the development of objective selfawareness and likely to be a function of children's corresponding understanding of others as psychological agents (Hoffman, 2007; Moore, 2006, 2007; Zahn-Waxler, Radke-Yarrow, et al., 1992).

In addition to growing social understanding, the motivational mechanisms involved in early prosocial behavior may undergo developmental change during toddlerhood. Not all the possible motivations for behaving prosocially are other oriented, perhaps especially in young children. For example, in a study by Rheingold (1982), 18-month-olds participated at high rates in "helping" their parents to set a table, sweep up bits of paper, put cards in a box, and so forth. However, the fact that children in the study often initiated an action even before the adult expressed a need or started to act points to the possibility that they may have simply enjoyed participating in social activities alongside adults, were seeking adults' approval, or found the activities themselves interesting or fun, rather than being concerned about the other's well-being. Even in older children and adults, prosocial behavior can be motivated by self-oriented concerns such as a desire for social approval, concrete rewards, or reciprocal prosocial responding (Eisenberg, 2005). It is 
possible, then, that very early instances of instrumental helping are motivated as much by more rudimentary forms of self-interest, or interest in the persons, objects, or actions involved, as by compassionate concern for others. Empathic helping, that is, prosocial responding grounded in other-oriented concern, may develop later along with children's growing understanding of others as independent agents with internal states that differ from children's own (Hoffman, 2007; Mascolo \& Fischer, 2007).

One purpose of the current study was to test this hypothesis by extending previous work on toddlers' instrumental helping (Rheingold, 1982; Warneken \& Tomasello, 2006) to include empathic helping and to test 2-year-olds as well as 1-yearolds. We built on the existing experimental work by Warneken and Tomasello (2006), in which they demonstrated that 1-year-old children readily help an adult instrumentally with a variety of goal-directed actions and do so more often than in comparable control tasks in which helping is not necessary. In the current study, we contrasted instrumental and empathic helping by presenting 18- and 30-monthold children with tasks in which they could help an adult by offering her an object that she needed, for example, bringing her an out-of-reach toy so she could continue an interrupted game, or giving her a blanket to make her warm. We expected that children would be more likely to demonstrate prosocial behavior when it involved helping someone to complete an interrupted action (instrumental helping) than when helping was based on inferring and alleviating another's negative internal state (empathic helping). We also expected that this difference would be greater for 18-month-olds than for 30-month-olds, who are more skilled at inferring others' internal states (Lewis \& Carpendale, 2002; Repacholi \& Gopnik, 1997) as well as more concerned about them (Radke-Yarrow, 1986; Spinrad \& Stifter, 2006; Zahn-Waxler, Radke-Yarrow, et al., 1992).

\section{Altruistic Helping}

Prosocial behavior, even when it is other oriented, may not always be genuinely altruistic. A child can give a hug to a distressed friend or bring Mom her mittens, which may improve the other person's well-being without diminishing the child's own well-being; in fact, such behaviors are often rewarded, for example, by a reciprocal hug or praise. To what extent are these behaviors altruistic? The answer to this question depends in part on how we define altruism. Scholars from different disciplines provide different definitions: In evolutionary biology, a behavior is deemed altruistic only when it raises the expected reproductive success of the recipient at the expense of the reproductive success of the donor (Kitcher, 1998), whereas psychologists generally use less strict terms, although their definitions, too, range in the degree of self-sacrifice required. Grusec, Davidov, and Lundell (2002) characterize altruistic behavior as intentional assistance to others that comes at a cost to the donor. Piliavin and Charng (1990) argue that altruistic behavior must be performed without expecting any external reward. The general agreement seems to be that for an act to be considered altruistic, the recipient's well-being must be the donor's ultimate goal (Batson et al., 2008; Foster, Wenseleers, \& Ratnieks, 2006); that is, the recipient's benefit must be perceived as an end in itself, not as a means to the achievement of some of the donor's other goals (Kitcher, 1998). When does the ability to act on behalf of others-without considering one's own interests and potentially at a cost to oneself-first emerge?

Young children may behave prosocially before they behave altruistically. Toddlers are notoriously poor at sharing their possessions, but with the rapid development of self- and other-understanding over the 2nd year their rates of sharing, helping and cooperating increase (Hay, 2006; Hay \& Cook, 2007; Smiley, 2001). However, it is possible that costly helping, especially when it involves sacrificing one's own possessions, may become more difficult, not less so, as children better understand ownership and the costs of sharing in the 3rd year of life (Fasig, 2000; Hay, Caplan, Castle, \& Stimson, 1991; Imbens-Bailey \& Pan, 1998). Thus, children's motivation to behave altruistically, subordinating their own interests to those of others, may instead decrease with advances in social understanding.

Although toddlers may be motivated to help others, few empirical studies have directly tested their willingness to help as a function of whether selfsacrifice is required or not (cf. Warneken \& Tomasello, 2008). Thus, the second purpose of the current study was to examine children's helping behavior in situations that involved someone else's belongings in comparison to situations that required the children to give up their own belongings altruistically (e.g., giving their own blanket brought from home to an adult who was feeling cold). Prior research has shown that children will sometimes give up something in their possession (e.g., Vaish, Carpenter, \& Tomasello, 2009), or willingly stop 
playing an interesting game (Warneken \& Tomasello, 2008) to help an adult in distress. Giving up something of one's own, especially an object from home, is still a different type of cost, and arguably a more stringent test of altruistic motivation insofar as it carries greater personal significance and value (Blake \& Rand, 2010). We expected children at both 18 and 30 months of age to help more often and more quickly in tasks that did not require them to sacrifice their own belongings. We also expected older children to be more altruistically motivated, hence to help more readily than younger children even in the face of a personal sacrifice; however, we entertained the possibility suggested by Hay et al. (1991) that older children could be less willing to give up something of their own.

\section{The Role of Adult Communication in Early Prosocial Behavior}

Prosocial behavior develops within the crucible of social interaction. It is through dyadic interaction with adults that young children's social understanding and responding are socialized and shaped (Dunn, 1988; Grusec, 2006). Notably, in most of the studies reviewed earlier adults used a variety of ostensive cues to communicate their emotions, intentions, or desires explicitly, often with exaggeration to make them salient and clear. Such communication may serve to scaffold children's attention to, interest in, and inferences about others' internal states and the characteristics of the objects or events toward which adults behave. Some researchers have found that infants require the supportive, mutual engagement of an adult to recognize what the adult is attending to (Moll, Carpenter, \& Tomasello, 2007) and that infants' ability to interpret others' behavior and to understand what another person feels, needs, or wants may initially depend on adults' scaffolding and communicative support (Carpendale \& Lewis, 2004; Ruffman, Slade, Devitt, \& Crowe, 2006; Tomasello, 1995). In a recent study of sharing in toddlers, it was shown that 24-montholds were able to infer and act on an adult's desire for a snack from the adult's explicit verbal expressions of desire, but not when the adult was silent (Brownell, Svetlova, \& Nichols, 2009). Prosocial behavior may therefore be more likely when adult communications make the other's needs, desires, and emotions more apparent and reduce the need for complex inferences about others' internal states.

The third purpose of our study was to examine how adults' communications support young children's prosocial responding. To this end, we systematically manipulated the expressive cues provided by the adult during the helping tasks. For each task, the adult made her need and how to help progressively more explicit with a fixed sequence of specific gestural, vocal, and verbal cues, for example, first simply vocalizing "Brrrr!" with shivering and shaking, then reaching toward an out-ofreach blanket with gaze alternation between the child and the blanket. The cues culminated in a direct request for a particular object (e.g., "Can you bring me the blanket?"). Children were assigned a helping score based on when in the sequence of cues they helped the adult. If they helped spontaneously without any supportive cueing from the adult, they received the maximum score, whereas they received the minimum score if they helped only when specifically requested to do so. We expected that 18-month-olds would receive lower scores than 30-month-olds, that is, that younger children's helping responses would depend on more explicit and direct communications about the adult's needs. We also expected that the communicative support from adults would become more necessary as the complexity of the inference about the other's internal states increased; thus, we expected that children would receive higher scores for instrumental helping than for empathic helping and higher scores for empathic helping than for altruistic helping.

\section{Overview of Design}

To examine the roles of developing social understanding, prosocial motivation, and adult communicative support in early prosocial behavior, we presented each child with nine tasks in which an adult needed help and the child could provide it by bringing a nearby object that the adult could not reach. We contrasted children's instrumental helping behavior in an "action" condition, in which the adult needed an object to complete a goal-directed action, with their empathic helping in an "emotion" condition, in which the adult needed an object to alleviate a negative emotion. Even though the target behavior was identical in the two conditions, we expected children to help more readily in the action condition than in the emotion condition. Because understanding of goal-directed behavior developmentally precedes the ability to infer and represent others' internal emotional states, we expected greater difference between the two conditions among 18-month-olds than among 30-montholds. We also contrasted children's instrumental and empathic helping with altruistic helping in 
which they had to give up something of their own to help the adult (the "altruism" condition). We expected children to help more readily when they did not have to sacrifice their own belongings. Finally, in each helping task we manipulated the adult's communications about her need and what could be done to help her. We expected younger children to require more communicative cues to support their helping behavior, especially in the emotion and the altruism conditions.

\section{Method \\ Participants}

Thirty-two 18-month-olds $(M=18.46$ months, $S D=0.48$; 15 boys and 17 girls) and thirty-three 30month-olds $(M=30.32$ months, $S D=0.68 ; 18$ boys and 15 girls) participated in the study. Seven additional children were tested but their data were not usable because of procedural error or the child's refusal to participate in any of the tasks. Participants came from working- and middle-class families from a medium-sized city and surrounding suburbs. Seventy-eight percent were Caucasian, $11 \%$ were Asian, $7 \%$ were African American, and $4 \%$ were Hispanic. All children were walking, talking, and were healthy and developing normally by parent report.

\section{General Procedure}

Children arrived to a laboratory playroom with their caregivers who remained in the room completing questionnaires and were asked not to encourage, reward, or comment on the child's behavior. Testing was conducted by a female experimenter (E) with the help of a female assistant (AE). The session began with a warm-up and familiarization period during which $\mathrm{E}$ and $\mathrm{AE}$ played with the child for several minutes to ensure that the child was comfortable approaching and interacting with both of them. During warm-up, E and AE also demonstrated various objects that were later used during testing, to be sure that children understood their use and to control for possible differential exposure prior to the study. Specifically, AE came in with messy hair and showed how to fix it with a hairclip, also giving the child a chance to play with the hairclip. She then gave a small stuffed toy with an attached hairclip to the child and told the child that both the toy and the hairclip were for him or her to take home (the toy accompanied the hairclip to make the gift equally interesting for girls and boys). AE also showed the child how a blanket could be wrapped around her shoulders to make her feel warm. E showed her teddy bear to the child, saying that it was her special toy that made her feel happy. Parents had been asked to bring the child's own blanket and favorite toy from home; thus, together with the newly acquired hairclip, there were three objects belonging to the child. Before the experiment started, AE placed all the objects behind a curtain; the objects were later retrieved as relevant in each testing episode. The experimental session was structured so that testing episodes were alternated with free-play episodes. The session was video recorded through a one-way mirror for later coding.

Nine helping tasks (one trial per task) were presented, in which $\mathrm{E}$ demonstrated difficulty or distress which could be alleviated by giving her a particular object. Prior to each trial, the target object (the one that $\mathrm{E}$ needed) and two distracter objects were placed on a tray out of E's reach, but within the child's reach. The distracter objects served as targets in other trials. On each trial, E provided up to eight progressively more explicit cues as to her need or emotion and what could help or comfort her. All tasks were administered within subjects. To control for possible fatigue or familiarization effects, the order of tasks was counterbalanced using a modified Latin square design, with a total of nine possible orders; no two tasks from the same condition ever occurred in a row. Approximately equal numbers of children received each order.

\section{Conditions and Tasks}

The nature of the inference that children had to make about E's need and the degree of sacrifice they had to make were manipulated via three conditions (action, emotion, and altruism), with three trials per condition. In the action condition, the child had to infer E's action-related goal (three trials); in the emotion condition, the child had to infer E's emotion or internal state (three trials). In both of these conditions, the needed object belonged to E. The altruism condition (three trials) was identical to the emotion condition except that the child had to give up something of his or her own to help or comfort E, thus requiring a sacrifice on the child's part to alleviate E's distress.

More specifically, in the action condition, E had difficulty completing three different goal-oriented actions involving objects that were out of reach because they had been dropped or misplaced; the child could help by bringing the object necessary to 
complete each action. This condition emphasized the interrupted action, not E's internal state. In the emotion and altruism conditions, E demonstrated three different negative internal states (sadness, cold, and frustration); the child again could help by bringing specific objects to $\mathrm{E}$. These conditions emphasized the adult's distress and the child's help served to alleviate the distress instead of completing an interrupted action.

The three trials in each condition were equated across conditions to ensure that the tasks were parallel, that is, involved the same behaviors and objects in each condition. The three task types in each condition were: (a) need for a clip for attaching something, (b) need for a blanket or cloth for wrapping, and (c) need for a toy for playing or comforting. Thus, the tasks were similar across conditions in terms of the target object needed and the specific helping behavior required, but they had different social-cognitive and motivational demands depending on the condition. For example, a clip could be handed to the experimenter to help her complete the action of clipping cloths to a line (action condition) or to alleviate her feeling of frustration with her messy hair (emotion and altruism conditions), with the clip belonging to the child in the altruism condition. Hence, the required helping behavior and the required object were identical in the three conditions (e.g., handing a clip to E), but helping in each condition required a different inference about the need of the recipient and/or a different motivation. Whereas in the action condition helping was based on understanding another person's goal and motivated by wanting to facilitate an interrupted goal-directed action, in the emotion condition it required understanding another person's internal state and wanting to alter that state, with an additional altruistic motivation in the altruism condition.

\section{Action Condition}

\section{Description of Tasks}

Clipping task (adapted from Warneken \& Tomasello, 2006). E is clipping square pieces of fabric to a clothesline and drops a clothespin out of reach. Child's target behavior: Hand the clothespin to E.

Wrapping task. E is wrapping wooden blocks in square pieces of fabric (sitting behind a small table), and runs out of wrappers on the final block. An additional wrapper is available on the tray which can be reached by the child but not by E. Child's target behavior: Hand the wrapper to E.
Toy task. E is playing with a toy car together with a toy driver that fits in the car, then absentmindedly places the car on the tray near the child to play another short game with the child. She then reseats herself behind the table and away from the tray picks up the driver to start playing again, but has no car. Child's target behavior: Hand the car to $\mathrm{E}$.

\section{Emotion Condition}

Clipping task. AE places the hairclip on the tray near the child and leaves. E enters the room with her hair in her eyes, sits on the floor out of reach of the tray, and demonstrates her frustration and distress with actions, moans, and sighs as she tries unsuccessfully to move her messy hair away from her face. Child's target behavior: Hand the hairclip to $\mathrm{E}$.

Wrapping task. E shows her blanket to the child, reminding the child that it makes her warm. She then places the blanket on the tray near the child as she begins a game with the child, moves out of reach of the tray, and sits on the floor. E suddenly becomes cold, shivering, rubbing her arms, and saying "Brrrr" with a distressed expression on her face. Child's target behavior: Hand the blanket to E.

Toy task. E shows her teddy bear to the child, reminding the child that it is her favorite toy and that it makes her happy. She then places the teddy bear on the tray near the child and moves out of reach of the tray. AE enters and whispers something to E, who immediately becomes sad, sighing and sobbing as she sits on the floor. Child's target behavior: Hand the teddy to $\mathrm{E}$.

\section{Altruism Condition}

Clipping task. AE places the child's hairclip (given to the child during the warm-up and attached to a stuffed toy) on the tray near the child and leaves. $\mathrm{E}$ enters the room with her hair in her eyes, sits on the floor out of reach of the tray, and demonstrates frustration with actions, moans, and sighs as she tries unsuccessfully to move her messy hair away from her face. Child's target behavior: Hand the child's own hairclip to E.

Wrapping task. E places the child's blanket, brought from home, on the tray near the child; she points it out and talks about it with the child, mentioning that it must be warm. She then begins a game with the child, moving out of reach of the tray, and sits on the floor. E suddenly becomes cold, shivering, rubbing her arms, and saying 
"Brrrr" while looking distressed. Child's target behavior: Hand the child's own blanket to E.

Toy task. E places the child's favorite toy, brought from home, on the tray near the child; she points it out and talks about it with the child, saying that it looks very special and must make the child happy. E then moves out of reach of the tray and suddenly receives a call on her cell phone, which makes her sad, and she begins to sigh and sob. Child's target behavior: Hand the child's own toy to E.

\section{Communicative Cues}

On each trial, the experimenter provided up to eight progressively more explicit cues about her need or emotion and what the child could do to help or comfort her. The cues and their order of presentation were the same across trials. The first two cues communicated the experimenter's state gesturally, then verbally (e.g., shivering; saying "I'm cold"); the third cue stated the general need (e.g., "I need something to make me warm"); the fourth cue drew the child's attention to the target object by labeling it (e.g., "a blanket!"); and the rest of the cues informed the child with increasing specificity about how to help or comfort the experimenter, with the final cue giving a very specific instruction (e.g., "Can you bring me the blanket?"). Table 1 displays the order of presentation and description of each of the eight cues.

Each cue was presented for 5-7 s. Once the child handed the target object to the experimenter, she stopped providing cues. If the child brought one of the distracter objects first, E took it from the child with a neutral facial expression and continued to provide cues until the child brought the target object. If the child did not bring the target object by the last cue, the experimenter got up and retrieved it herself without reaction or comment and then proceeded to the next play episode. To reduce the possibility of simple compliance or attempts to seek adult approval, the experimenter did not thank, praise, or reward the child when the child brought the object, but instead neutrally described the result (e.g., "Now I can clip," "Now I feel warm").

\section{Measures}

Children's responses to each helping task were coded from video records. For each task, the child received a "target helping score," corresponding to the specific cue in the sequence of eight communicative cues when the child brought the target object to the experimenter (see Table 1 for the scores assigned to each cue). Higher scores represent more skilled responding, that is, earlier responses in the cue sequence, requiring less social and communicative support. A child who did not bring the target object by the final cue on a given task received a score of 0 for that task. As an indicator of their general propensity to help, children were also coded for whether they brought any object, either target or distracter, at any cue level, for each task (coded 0 or 1 ). Video records were coded by two trained research assistants blind to the study's hypotheses. Reliability was calculated on $21 \%$ of the data, resulting in a weighted $k=.89$.

\section{Results}

Preliminary analyses were conducted to check for gender, task, and task order effects. No differences

Table 1

Communicative Cues and Corresponding Helping Scores

\begin{tabular}{|c|c|c|}
\hline $\begin{array}{l}\text { Order of } \\
\text { presentation }\end{array}$ & Description & $\begin{array}{l}\text { Helping score } \\
\text { assigned }\end{array}$ \\
\hline 1 & $\begin{array}{l}\text { Facial/bodily/vocal expression of general need (e.g., hands up, looking around, "hmmm") or internal } \\
\text { state (e.g., shivering with cold, rubbing and hugging oneself to get warm, "brrrr") }\end{array}$ & 8 \\
\hline 2 & Naming the interrupted action (e.g., "I can't clip!") or internal state (e.g., "I am sad") & 7 \\
\hline 3 & $\begin{array}{l}\text { Verbal expression of a general need for an object (e.g., "I need something to clip with" or } \\
\text { "I need something to make me feel warm") }\end{array}$ & 6 \\
\hline 4 & Naming the specific object that would meet the need (e.g., "A clothespin!" or "A blanket!") & 5 \\
\hline 5 & Alternating gaze between the object and the child, as a nonverbal request to get the object & 4 \\
\hline 6 & Reach and gesture toward the object, as a more explicit request to get the object & 3 \\
\hline 7 & General verbal request for help ("Can you help me?") & 2 \\
\hline 8 & Specific verbal request (e.g., "Can you bring me the blanket?") & 1 \\
\hline
\end{tabular}


were found for gender or task order on any outcome variable, so all subsequent analyses were conducted on data collapsed over gender and order. Overall, task effects varied unsystematically across conditions, suggesting that no particular type of task was more or less familiar or difficult than others; in particular, tasks did not differ in difficulty within the emotion condition. Analyses also showed that task did not interact with order or gender to affect performance, nor did order interact with condition.

Two sets of substantive analyses are presented. The first set addressed general questions about whether 30-month-olds helped more often across contexts and manipulations than did 18-montholds, and whether their helping was more specific and appropriate. The second set of analyses examined age and condition differences in how readily children helped and how much communicative support they needed, using the target helping score as the dependent measure.

\section{General Propensity to Help and Appropriateness of Help}

To examine age differences in children's general propensity to help the experimenter, we analyzed the number of times children brought any object (either the target or the distracter object) across all nine trials, regardless of the cue level at which they did so. All children exhibited some degree of helping toward the experimenter. Among 18-montholds, every child helped by bringing some object on at least two of the nine trials, and $44 \%$ helped on all nine. Among 30-month-olds, every child helped on at least six of the nine trials, and $84 \%$ helped on all nine. An independent-samples $t$ test on the mean number of helping responses yielded a significant age difference, with 30-month-olds helping more often $(M=8.74, S D=0.68)$ than 18 -montholds $(M=7.40, S D=1.88), t(61)=3.72, p<.001$. Thus, older children were more inclined to help overall, but even younger children helped, on average, on more than seven of the nine opportunities. It is important to note, however, that this includes instances of directed or instructed helping when the experimenter specifically requested the target object by name (e.g., "Can you bring me the blanket?"), as well as instances of helping by bringing the distracter object, that is, without discriminating whether the object was the one that the experimenter actually needed.

To examine children's ability to help appropriately by bringing the specific object that the adult needed, we conducted a two-way repeated measures analysis of variance (ANOVA) with age group (18 and 30 months) as the between-subjects factor, and condition (action, emotion, altruism) as the within-subjects factor, on the mean number of times children brought the target object, regardless of cue level (see Figure 1). Across conditions, older children brought the target object significantly more often $(M=2.87$ out of three trials per condition, $S D=0.38)$ than did younger children $(M=2.31$, $S D=0.51), F(1,61)=14.73, p<.001$. There was also a significant effect of condition, $F(2,122)=19.16$, $p<.001$. Post hoc pairwise comparisons (LSD) revealed that children of both ages brought the target significantly more often in the action condition $(M=2.84, S D=0.41)$ than in the emotion condition $(M=2.69, S D=0.67), p=.03$, and significantly more often in the emotion condition than in the altruism condition $(M=2.24, S D=0.98), p=.001$. The interaction was not significant. Thus, collapsing across cue levels, 30-month-olds more often helped and more often helped appropriately by bringing the object that the experimenter actually needed. All children tended to exhibit more appropriate helping in the action condition than in the emotion and the altruism conditions.

\section{How Readily Children Helped as a Function of Age and Helping Condition}

To determine whether there were age or condition differences in how readily children helped, that is, how much communicative support they needed to help appropriately, a two-way repeated measures ANOVA, with age group (18 and 30 months) as the between-subjects factor and condition (action, emotion, altruism) as the withinsubjects factor, was conducted on the target helping scores. Higher scores corresponded to earlier, more

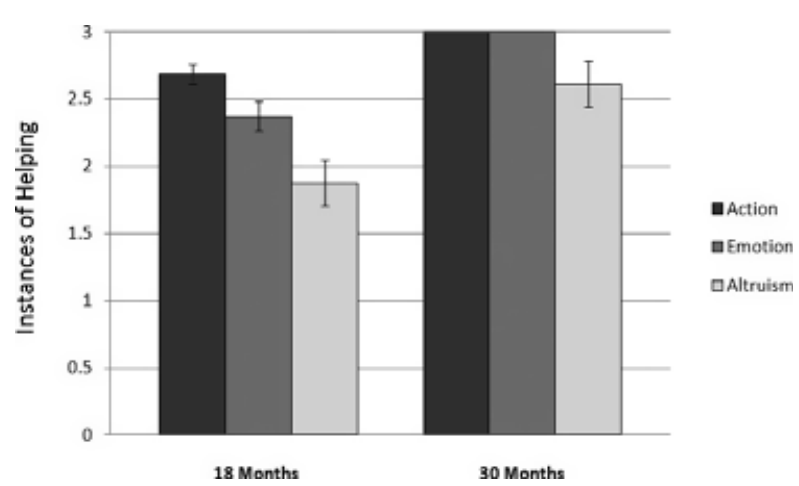

Figure 1. Mean number of times $( \pm S E)$ children helped by age and condition (out of three possible instances per condition). 
skilled helping with less communicative support from the adult. Nonparametric analyses for ordinal data produced identical results.

A significant difference between age groups was found, $F(1,61)=61.99, p<.001$. Across conditions, 30 -month-olds helped more readily, that is, at earlier cue levels $(M=5.41, S D=1.14)$, than did 18month-olds $(M=3.25, S D=1.07)$. There was also a significant effect of condition, $F(2,122)=68.04$, $p<.001$. Post hoc comparisons (LSD) revealed that across ages, children helped more readily in the action condition $(M=5.62, S D=1.70)$ than in the emotion condition $(M=4.28, S D=2.01), p<.001$, and in the emotion condition than the altruism condition $(M=3.09, S D=1.77), p<.01$.

These main effects were qualified by a significant interaction between age and condition, $F(2$, 122 ) $=5.91, p<.001$ (see Figure 2). Younger children needed significantly less communicative support to help in the action condition $(M=4.64$, $S D=1.75)$ than in either the emotion condition $(M=2.79, S D=1.55), t(31)=6.26, p<.001$, or the altruism condition $(M=2.33, S D=1.44), t(31)=$ $7.08, p<.001$, which did not differ from each other, $t(31)=1.75$, ns. Older children, on the other hand, helped more readily in the action condition $(M=6.61, S D=0.88)$ than in the emotion condition $(M=5.77, S D=1.26), t(30)=3.21, p=.003$, and more readily in the emotion condition than in the altruism condition $(M=3.85, S D=1.76), t(30)=$ $5.49, p<.001$.

As a more stringent test of children's ability to help, we conducted nonparametric tests on the number of children who helped immediately by bringing the target object after the initial communi-

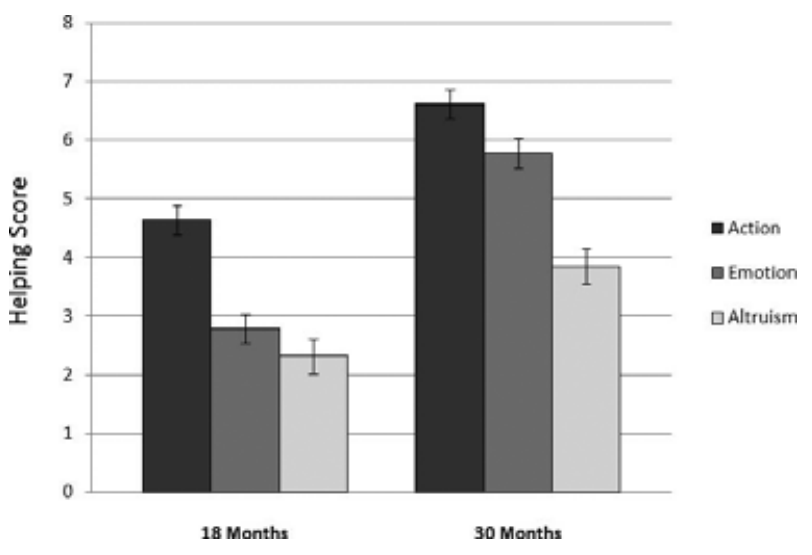

Figure 2. Mean target helping scores $( \pm S E)$ by age and condition.

Note. Higher scores indicate earlier helping with less communicative support. cative cue from the experimenter (i.e., nonverbal expression of need). Among 18-month-old children, $44 \%$ helped the adult immediately and appropriately on one or more of the tasks in the action condition (out of three); that is, they brought the target object when the adult first registered her difficulty with facial expression, vocalization, and/or posture. In the emotion condition, this dropped to $13 \%$, and in the altruism condition only $6 \%$ of 18 -month-olds helped the adult immediately at least once. Among 30-month-olds, 87\% helped immediately one or more times in the action condition, as did $64 \%$ in the emotion condition, but only $18 \%$ helped immediately at least once in the altruism condition. Age differences in the number of children who helped immediately one or more times were significant for the action condition, $\chi^{2}=20.30, p<.001$, and the emotion condition, $\chi^{2}=18.30, p<.001$, but not for the altruism condition, $\chi^{2}=2.43$, ns.

\section{Discussion}

In this study, we examined early developments in young children's ability to help others in need. Our data confirmed previously reported findings that toddlers as young as 18 months are able to help adults instrumentally, and that the propensity to respond prosocially grows significantly between 18 and 30 months of age. The particular novelty of this study was in the manipulation of factors that could underlie helping behaviors at each of the examined ages, specifically, the nature of the inference that the child had to make about the other's need, the cost of helping to the child, and the amount of communicative support provided by the adult in need of help. By varying these factors we aimed to clarify possible social-cognitive and motivational mechanisms that support early prosocial behavior and its development in the 2nd and 3rd years of life. Helping an adult instrumentally to complete an interrupted action-related goal was significantly easier than empathic helping to alleviate an adult's emotional distress, particularly for 18-month-olds. Helping was also easier when it did not require children to give up something that belonged to them, at both 18 and 30 months. We also found that 18-month-olds' helping required significantly greater communicative support and scaffolding from an adult than that of 30-month-olds, whose prosocial behavior was more autonomous and demonstrated greater social understanding. 
Age-Related Differences in Helping and Requisite Adult Communication

Prosocial responses emerge early in the 2nd year of life (Rheingold, 1982; Warneken \& Tomasello, $2006,2007)$ and increase over childhood in concert with growing self-other differentiation and social understanding (Bischof-Kohler, 1991; Brownell \& Carriger, 1990; Moore, 2006; Zahn-Waxler, RadkeYarrow, et al., 1992). However, prosocial responses among 1-year-olds are infrequent, occur more reliably for familiar situations and emotion contexts (e.g., pain; Zahn-Waxler, Radke-Yarrow, et al., 1992) than for less familiar situations (e.g., sadness, fatigue; Sigman, Kasari, Kwon, \& Yirmiya, 1992), and can be increased by explicit requests for assistance (Rheingold, 1982; Spinrad \& Stifter, 2006). Even at age 2, prosocial behavior remains irregular and does not occur reliably across trials or tasks (Demetriou \& Hay, 2004; Hay, 2006).

In the current study, both 18- and 30-month-old children helped the experimenter on the majority of trials. However, these apparently high helping rates included instances in which the adult explicitly requested help from the child and specified what was needed. Furthermore, when we consider the particular circumstances under which 18-month-olds helped, it becomes clear that their performance was mostly accounted for by helping in the action-related tasks, in which the experimenter had difficulty completing a goal-directed action. For emotion-related tasks, where children had to infer the adult's internal state and intervene to alleviate it, 18-month-olds were unlikely to help unless they received substantial communicative support and scaffolding from the adult. On average, the younger group tended to respond after the adult had expressed her internal state or need in different ways and had named the target object. Thirty-month-olds exceeded 18-month-olds on all measures of prosocial behavior in all conditions. As predicted, not only did older children help more frequently, but they also required less communicative support from the adult, tending to help before the adult had named the object that she needed. Thus, 18-month-olds are most able to respond prosocially in situationally obvious, goaloriented helping situations when they are supported by very clear communications about what the other person needs and what can be done to mitigate the need. By 30 months of age, children's greater ability to infer another's needs from more general information and more subtle cues permits them to recognize another's need for help more easily and to rely less on the adult for this information.

One implication of these findings is that very early prosocial responding depends on social and communicative support from others about their needs and how the child can help. Several investigators of early social-cognitive development, starting with Vygotsky (1978), have emphasized the essential role of partner support when children first acquire new knowledge and skills. In a classic study of 6- to 18-month-old infants and their mothers, Bakeman and Adamson (1984) showed that new forms of social engagement first appeared embedded in and supported by the social interaction context. In their study, mothers initially acted in ways that scaffolded their infants' performance before infants were capable of such performance on their own; with age and repeated exposure, infants themselves exhibited more skilled and autonomous forms of engagement. We can speculate that new forms of social understanding and the corresponding prosocial responses are socialized in a similar way. In the current study, tasks with more challenging social-cognitive demands required more prolonged, specific, and explicit communication; with age, children's need for such communication decreased. While human infants may have a natural predisposition to be prosocial early in development (Warneken \& Tomasello, 2009), social and communicative support from adults appears to be important in scaffolding young children's understanding of when and how to enact prosocial responses.

\section{Social Understanding: Actions Versus Emotions}

In line with our expectations, instrumental, action-related tasks elicited the most robust helping responses and required the least scaffolding from an adult. Even for 30-month-olds helping in the action condition was significantly easier than in the other two conditions. This is consistent with existing research on development of early social understanding that has shown that by the middle of the 2nd year of life children are able to understand other people's goals and intentions (Meltzoff, 1995; Tomasello, Carpenter, Call, Behne, \& Moll, 2005). Even though emotion understanding also undergoes important developments in this period (Eisenberg, 2005; Mascolo \& Fischer, 2007), enabling some forms of empathy (Spinrad \& Stifter, 2006; Zahn-Waxler, Radke-Yarrow, et al., 1992), empathic helping appears to be more complex than helping with action-related tasks. Unlike helping based on predicting action-effect outcomes in observable 
actions (Csibra \& Gergely, 2007), helping in response to others' emotions requires an additional step in social-cognitive processing, as inferring the goal in this case follows from inferring someone's internal state. Furthermore, emotion-related tasks can lead to personal distress in young children via emotion contagion, perhaps especially when others are in pain or evident distress. This requires young children both to differentiate their own distress from the other's distress and to regulate their own distress if they are to exhibit empathic helping based on other-oriented concern or sympathy rather than based on the wish to reduce their own personal distress (Eisenberg, 2005; Hoffman, 1975). As a result, both cognitive and affective demands are greater in empathic helping compared to instrumental, action-related helping. The ability to understand and assist others with goal-directed actions may represent the first step toward this more complex social understanding and associated prosocial responses.

Together with other recent research, the current study points to an important transition from instrumental helping to empathic helping late in the 2nd year of life and early in the 3rd. Warneken and Tomasello (2007) demonstrated that 14-montholds are able to help adults in only the most straightforward instrumental tasks, those involving reaching. Between 18 and 24 months of age, toddlers are able to help in a wider array of instrumental tasks that include difficulties with tools, obstacles, means-end relationships and the like, suggesting more advanced understanding of others' action-related goals (Warneken \& Tomasello, 2006). In the current study, by contrasting instrumental and empathic helping, we discovered that empathic helping is quite limited at 18 months but relatively skilled by 30 months of age. The developmental picture suggested by integrating these findings is that by 14 months of age, toddlers are able to help others with simple, goal-directed actions; by 18-24 months they can help in actionrelated situations that are more demanding cognitively but still relatively transparent with respect to another's goals and needs; and by 30 months of age, they are able to help in emotion-related situations requiring more complex inferences about others' needs based on inferring others' feelings and internal states.

\section{Altruistic Motivation: Cost Versus No Cost}

The altruism condition, in which helping required the child to give his or her own possession to the experimenter, was included in the design to examine the motivational component of early prosocial behavior. Recall that the only difference between the altruism and emotion conditions was whether the objects needed by the adult were the child's own or the adult's. As the two conditions were otherwise identical, any differences in helping must have been due to affective or motivational, rather than cognitive, mechanisms. As expected, the altruism condition was the most difficult for both ages. Interestingly, however, 18-month-olds' behavior did not differ significantly for the emotion condition versus the altruism condition. Indeed, their helping scores were near the floor in both. In other words, whether a sacrifice was involved or not, 18-month-olds had an equivalently difficult time understanding the adult's emotion-related needs and required substantial input from the adult to come up with a helping response. Among 30month-olds, however, both the rates of helping and how early in the cue sequence children responded differed significantly between the altruism and emotion conditions, even though the social-cognitive demands were identical. Although 30-montholds knew about the adult's need and how to help in the emotion tasks, they were less willing to provide costly help in the altruism tasks. For the younger group, therefore, the challenge seemed to be in disentangling the complex social understanding demands of the emotion-related tasks, whereas the older group had the most difficulty with overcoming their possessiveness and giving up something of value.

These findings suggest that very young children exhibit a general prosocial motivation, readily providing instrumental help to an adult when the amount of information about what is needed corresponds to their level of social understanding. Yet, when the demands of the task involve a sacrifice-giving their own possession to alleviate another's distress-this motivation is reduced. Grusec et al. (2002), among others, define prosocial behavior as any intentional action that produces a positive outcome for the recipient, whereas altruism implies that assistance to others comes at some cost to the donor. The fact that instances of costly helping in the current study were quite low and often occurred in response to an adult's direct and explicit request suggests that toddlers' helping responses were unlikely to be genuinely altruistic. Altruistic motivation appears to be a later developing phenomenon, which may build upon the more basic prosocial motivation emerging and developing in toddlerhood. 
Several limitations of this study are worth noting. First, the contrast between the action condition and emotion condition was not as strong as it could be in some respects, but in other respects may have been too distinct. For example, the emotion of frustration is in part a response to a blocked goal (Witherington, Campos, \& Hertenstein, 2001) and as operationalized in the current study also has an action component (e.g., moving one's hair away from one's face). Clearer distinctions between these conditions might produce clearer developmental differences between instrumental and empathic helping. Another limitation is the absence of an action version of the altruism condition, thereby constraining our examination of altruistic responding to empathyrelated helping situations. Future research could address whether altruism emerges earlier in instrumental helping than in empathy-related helping contexts. Finally, perhaps some children failed to help because they chose not to help, believing that adults bear responsibility for helping others (Caplan \& Hay, 1989). In particular, it is possible that rates of helping among the older children in the altruism condition were underestimated in the current study if such factors were in operation. One way future research might address this question is by manipulating the circumstances under which helping occurs, such as presence of parents or other adults in the room, or manipulating the value of the to-be-shared object in addition to whether it belongs to the child or not.

In sum, the findings of the current study reveal an important developmental transition at the end of the 2nd year of life when toddlers' helping behavior expands to include empathic as well as instrumental helping. The results point as well to the late emergence of altruistic helping, after other-oriented helping first becomes evident, inasmuch as even 2-year-olds find costly helping especially difficult. This suggests that changes in social understanding and prosocial motivation may be closely linked, with other-oriented concern developing in concert with growth in children's ability to represent and understand others' subjective internal states, and altruistic helping developing later, in concert with understanding of social and moral norms. It would be productive in future research to investigate these links more directly, possibly by including additional measures of selfand other-understanding and empathy, as well as by testing older children in situations that require various types of helping.

\section{References}

Bakeman, R., \& Adamson, L. B. (1984). Coordinating attention to people and objects in mother-infant and peer-infant interaction. Child Development, 55, 12781289.

Batson, C. D., Ahmad, N., Powell, A. A., \& Stocks, E. L. (2008). Prosocial motivation. In J. Y. Shah \& W. L. Gardner (Eds.), Handbook of motivation science (pp. 135149). New York: Guilford.

Bischof-Kohler, D. (1991). The development of empathy in infants. In M. E. Lamb \& H. Keller (Eds.), Infant development: Perspectives from German-speaking countries (pp. 245-273). Hillsdale, NJ: Erlbaum

Blake, P., \& Rand, D. (2010). Currency value moderates equity preference among young children. Evolution and Human Behavior, 31, 210-218.

Brownell, C. A., \& Carriger, M. S. (1990). Changes in cooperation and self-other differentiation during the second year. Child Development, 61, 1164-1174.

Brownell, C. A., \& Kopp, C. B. (2007). Socioemotional development in the toddler years: Transitions and transformations. New York: Guilford.

Brownell, C. A., Svetlova, M., \& Nichols, S. (2009). To share or not to share: When do toddlers respond to another's needs? Infancy, 14, 117-130.

Caplan, M. Z., \& Hay, D. F. (1989). Preschoolers' responses to peers' distress and beliefs about bystander intervention. Journal of Child Psychology and Psychiatry, 30, 231-242.

Carpendale, J. I., \& Lewis, C. (2004). Constructing an understanding of mind: The development of children's social understanding within social interaction. Behavioral \& Brain Sciences, 27, 79-96.

Csibra, G., \& Gergely, G. (2007). "Obsessed with goals": Functions and mechanisms of teleological interpretation of actions in humans. Acta Psychologica, 124, 60-78.

Demetriou, H., \& Hay, D. F. (2004). Toddlers' reactions to the distress of familiar peers: The importance of context. Infancy, 6, 299-318.

Dunn, J. (1988). The beginnings of social understanding. Cambridge, MA: Harvard University Press.

Eisenberg, N. (2005). The development of empathyrelated responding. In G. Carlo \& C. P. Edwards (Eds.), Moral motivation through the life span (pp. 73-117). Lincoln: University of Nebraska Press.

Fasig, L. G. (2000). Toddlers' understanding of ownership: Implications for self-concept development. Social Development, 9, 370-382.

Fehr, E., \& Rockenbach, B. (2004). Human altruism: Economic, neural, and evolutionary perspectives. Current Opinion in Neurobiology, 14, 784-790.

Flavell, J. H. (1999). Cognitive development: Children's knowledge about the mind. Annual Review of Psychology, 50, 21-45.

Foster, K. R., Wenseleers, T., \& Ratnieks, F. (2006). Kin selection is the key to altruism. Trends in Ecology and Evolution, 21(2), 57-60. 
Gergely, G., Egyed, K., \& Kiraly, I. (2007). On pedagogy. Developmental Science, 10, 139-146.

Grusec, J. E. (2006). The development of moral behavior and conscience from a socialization perspective. In M. Killen \& J. G. Smetana (Eds.), Handbook of moral development (pp. 243-265). Mahwah, NJ: Erlbaum.

Grusec, J. E., Davidov, M., \& Lundell, L. (2002). Prosocial and helping behavior. In P. K. Smith \& C. H. Hart (Eds.), Blackwell handbook of childhood social development (pp. 457-474). Malden, MA: Blackwell.

Hay, D. F. (2006). Yours and mine: Toddlers' talk about possessions with familiar peers. British Journal of Developmental Psychology, 24, 39-52.

Hay, D. F., Caplan, M., Castle, J., \& Stimson, C. A. (1991). Does sharing become increasingly "rational" in the second year of life? Developmental Psychology, 27, 987-993.

Hay, D. F., \& Cook, K. V. (2007). The transformation of prosocial behavior from infancy to childhood. In C. A. Brownell \& C. B. Kopp (Eds.), Socioemotional development in the toddler years: Transitions and transformations (pp. 100-131). New York: Guilford.

Hoffman, M. L. (1975). Developmental synthesis of affect and cognition and its implications for altruistic motivation. Developmental Psychology, 11, 607-622.

Hoffman, M. L. (2007). The origins of empathic morality in toddlerhood. In C. A. Brownell \& C. B. Kopp (Eds.), Socioemotional development in the toddler years: Transitions and transformations (pp. 132-145). New York: Guilford.

Imbens-Bailey, A., \& Pan, B. A. (1998). The pragmatics of self- and other-reference in young children. Social Development, 7(2), 219-233.

Kitcher, P. (1998). Psychological altruism, evolutionary origins, and moral rules. Philosophical Studies, 89, 283-316.

Lewis, C., \& Carpendale, J. (2002). Social cognition. In P. K. Smith \& C. H. Hart (Eds.), Blackwell handbook of childhood social development (pp. 376-393). Malden, MA: Blackwell.

Liszkowski, U., Carpenter, M., Striano, T., \& Tomasello, M. (2006). 12-and 18-month-olds point to provide information for others. Journal of Cognition and Development, 7, 173-187.

Mascolo, M. E., \& Fischer, K. W. (2007). The codevelopment of self and sociomoral emotions during the toddler years. In C. A. Brownell \& C. B. Kopp (Eds.), Socioemotional development in the toddler years: Transitions and transformations (pp. 66-99). New York: Guilford.

Meltzoff, A. N. (1995). Understanding the intentions of others: Re-enactment of intended acts by 18-month-old children. Developmental Psychology, 31, 1-16.

Moll, H., Carpenter, M., \& Tomasello, M. (2007). Fourteen-month-olds know what others experience only in joint engagement. Developmental Science, 10, 826-835.

Moore, C. (2006). The development of commonsense psychology. Mahwah, NJ: Erlbaum.

Moore, C. (2007). Understanding self and others in the second year. In C. A. Brownell \& C. B. Kopp (Eds.), Socioemotional development in the toddler years: Transitions and transformations (pp. 43-65). New York: Guilford.
Moore, C., \& Povinelli, D. J. (2007). Differences in how 12- and 24-month-olds interpret the gaze of adults. Infancy, 11, 215-231.

Perner, J., \& Ruffman, T. (2005). Infants' insight into the mind: How deep? Science, 308(5719), 214-216.

Piliavin, J. A., \& Charng, H.-W. (1990). Altruism: A review of recent theory and research. Annual Review of Sociology, 16, 27-65.

Radke-Yarrow, M. (1986). Affective development in young children. In T. B. Brazelton \& M. W. Yogman (Eds.), Affective development in infancy (pp. 145-152). Westport, CT: Ablex.

Repacholi, B. M., \& Gopnik, A. (1997). Early reasoning about desires: Evidence from 14- and 18-month-olds. Developmental Psychology, 33, 12-21.

Rheingold, H. L. (1982). Little children's participation in the work of adults, a nascent prosocial behavior. Child Development, 53, 114-125.

Ruffman, T., Slade, L., Devitt, K., \& Crowe, E. (2006). What mothers say and what they do: The relation between parenting, theory of mind, language and conflict/cooperation. British Journal of Developmental Psychology, 24, 105-124.

Sigman, M. D., Kasari, C., Kwon, J.-H., \& Yirmiya, N. (1992). Responses to the negative emotions of others by autistic, mentally retarded, and normal children. Child Development, 63, 796-807.

Silk, J., Brosnan, S., Vonk, J., Henrich, J., Povinelli, D., Richardson, A. S., et al. (2005). Chimpanzees are indifferent to the welfare of unrelated group members. Nature, 437, 1357-1359.

Smiley, P. A. (2001). Intention understanding and partersensitive behaviors in young children's peer interactions. Social Development, 10, 330-354.

Spinrad, T. L., \& Stifter, C. A. (2006). Toddlers' empathyrelated responding to distress: Predictions from negative emotionality and maternal behavior in infancy. Infancy, 10, 97-121.

Stevens, J. R., \& Hauser, M. D. (2004). Why be nice? Psychological constraints on the evolution of cooperation. Trends in Cognitive Sciences, 8, 60-65.

Tomasello, M. (1995). Joint attention as social cognition. In C. Moore \& P. J. Dunham (Eds.), Joint attention: Its origins and role in development (pp. 103-130). Hillsdale, NJ: Erlbaum.

Tomasello, M. (2008). Origins of human communication. Cambridge, MA: MIT Press.

Tomasello, M., Carpenter, M., Call, J., Behne, T., \& Moll, H. (2005). Understanding and sharing intentions: The origins of cultural cognition. Behavioral and Brain Sciences, 28, 675-691.

Vaish, A., Carpenter, M., \& Tomasello, M. (2009). Sympathy through affective perspective taking and its relation to prosocial behavior in toddlers. Developmental Psychology, 45, 534-543.

Vygotsky, L. S. (1978). Mind in society: The development of higher psychological processes. Oxford, England: Harvard University Press. 
Warneken, F., \& Tomasello, M. (2006). Altruistic helping in human infants and young chimpanzees. Science, 311(5765), 1301-1303.

Warneken, F., \& Tomasello, M. (2007). Helping and cooperation at 14 months of age. Infancy, 11, 271-294.

Warneken, F., \& Tomasello, M. (2008). Extrinsic rewards undermine altruistic tendencies in 20-month-olds. Developmental Psychology, 44, 1785-1788.

Warneken, F., \& Tomasello, M. (2009). The roots of human altruism. British Journal of Psychology, 100, 445-471.

Witherington, D. C., Campos, J. J., \& Hertenstein, M. J. (2001). Principles of emotion and its development in infancy. In G. Bremner \& A. Fogel (Eds.), Blackwell handbook of infant development (pp. 427-464). Malden, MA: Blackwell.

Woodward, A. L. (1998). Infants selectively encode the goal object of an actor's reach. Cognition, 69, 1-34.

Zahn-Waxler, C., \& Radke-Yarrow, M. (1990). The origins of empathic concern. Motivation and Emotion, 14, 107130.

Zahn-Waxler, C., Radke-Yarrow, M., Wagner, E., \& Chapman, M. (1992). Development of concern for others. Developmental Psychology, 28, 126-136.

Zahn-Waxler, C., Robinson, J. L., \& Emde, R. N. (1992). The development of empathy in twins. Developmental Psychology, 28, 1038-1047. 